\title{
14. Enabling Environments: the Role of the Law
}

\author{
CHRISTINE STEWART
}

\section{The 'Enabling Environment'}

In the context of HIV prevention, a distinction may be drawn between approaches which aim to persuade individuals to change their behaviour, and approaches which enable behaviour change by focusing on the social and environmental factors which assist or impede that change. These enabling approaches are directed towards removing barriers to protective and preventive action, and constructing barriers to the taking of risks (Tawil, Verster and O'Reilly 1995). The provision of an enabling social environment becomes all the more necessary when we consider how much the success of individual 'persuasion' approaches depends on a vast range of socio-cultural, historical and psychological factorsfactors which vary not only from country to country, but between individual communities in a country as culturally diverse as Papua New Guinea, and which often sabotage even the most well-designed prevention efforts.

\section{Why 'Enabling'?}

It is generally considered by the international community that repressive measures to combat HIV simply drive those affected underground and fuel the epidemic (Jenkins and Sarkar 2004; UNHCR /UNAIDS1996). Thus people who know that their HIV status will not be kept confidential will not come forward to be tested. People who know that they will be thrown out of their homes, workplaces or communities will not seek medical or counselling assistance. People who have already suffered HIV and AIDS discrimination face increased economic burdens of health care and providing for dependents, and will turn to risk behaviours for survival. People who are members of criminalised groups, such as sex workers, are unable to assert their rights in situations of violence and exploitation. 
But it has proved incredibly difficult to persuade the general Papua New Guinean community of this simple message: that repressive measures do not stop the epidemic, they actually assist its spread. Even in the most informed and articulate sectors of society, and despite the passage of the HIV/AIDS Management and Prevention Act (HAMP Act) through parliament in 2003, which recognised the counterproductivity of repressive measures, objections are still often raised to almost every proposal for an enabling environment. 'Mandatory testing is essential in the workplace, for planning purposes.' 'Sex workers should be all locked up, because they spread infection.' 'Giving condoms to teenagers will simply encourage them to experiment with sex.' 'Decriminalising homosexuality is not necessary because it is an expatriate import and not part of traditional Papua New Guinean culture.' 'Infected people should be driven from their homes and communities because contact with them or any of their possessions will cause infection to others.' 'Women spread HIV and should be raped as punishment.' 'Positive people should all be banished to a remote island.' And so on.

\section{The Role of the Law}

It has often been said that law cannot change behaviour. And it is true that law, even when properly implemented, often has little direct effect on people's choices, as has been realised by generations of criminologists attempting to discover why deterrence has not had the hoped-for effect of stamping out crime (Norrie 1993). But law, in whatever form, has always been seen as central to social existence and in recent years, social theorists have increasingly acknowledged the crucial role of law in shaping societies, particularly in colonial and post-colonial conditions (Merry and Brenneis 2004). Law, with its purpose of regulating, by its distribution of power and legitimacy, by its affording or denying certain resources to society for the resolution of conflict, has a significant role to play in the erection or removal of barriers to social action, and hence in the creation of the enabling environment we are aiming for.

The importance of law reform in the provision of an enabling environment for HIV prevention and management has been acknowledged at the highest levels. In 1996, an International Consultation on HIV/AIDS and Human Rights produced the HIV/AIDS and Human Rights International Guidelines. These Guidelines are aimed at providing

an environment in which human rights are respected [which] ensures that vulnerability to HIV/AIDS is reduced, those infected with and 
affected by HIV/AIDS live a life of dignity without discrimination and the personal and societal impact of HIV infection is alleviated (UNHCR/ UNAIDS 1996, 2).

The Guidelines recommend a national approach of widespread reform of laws and legal service provision, with an emphasis on anti-discrimination, protection of public health and improvement in the status of women, children and marginalised groups. They were followed in 1999 by a joint publication of UNAIDS and the Inter-Parliamentary Union, the 'Handbook for Legislators' (UNAIDS/IPU 1999) which fleshed out many of the recommendations in the Guidelines. The principles contained in these two documents were adopted by the South Pacific Commission in its Regional Strategy (SPC 1997) and by Papua New Guinea in its national plans (PNG/UN 1998; PNG/NACS 2006) as well as the HAMP Act.

Nevertheless, it must be acknowledged that law reform has its limitations. For a start, a legal regime is at best no more than an enabling device. It is only the first step in a three-stage process. The second is implementation. The third is the monitoring and, where necessary, enforcement of implementation. Even the best law reform cannot achieve, by several strokes of the pen, such wholesale social change as the empowerment of women. Nor can law reforms reach all levels of society. This is all the more so in a country such as Papua New Guinea, with over 800 different societies, most of them located both physically and conceptually far from the centre of government power; where the provision of government services is inexorably deteriorating and economic opportunities are limited; where the introduced common law system competes with or has achieved uneasy syncretism with custom and its more modern manifestation 'customary law'; and where state law, if it has penetrated to any degree at all, is ill-understood and inadequately applied by law and justice institutions and enforcers. However, this is no reason to ignore the potential of law reform to assist change, while nevertheless recognising its limitations and the external factors upon which it depends for effect.

\section{Law Reforms which can Promote an Enabling Environment in Papua New Guinea}

A case study is provided by an incident, now known as the Three-Mile Guesthouse Raid, which took place in Port Moresby one Friday afternoon in March 2004 (see Fletcher and Gonapa this volume; Jenkins this volume). ${ }^{1}$ The

1 This account is drawn from newspaper reports and statements from various people involved at the time (Pilimbo 2004, Yiprukaman 2004a, Yirpukaman 2004b, Hershey 2004). 
police raided a guesthouse which also operated a bar with gaming machines. There are a number of these guesthouses in Papua New Guinean towns providing short- and long-term accommodation at the lower end of the socio-economic scale. ${ }^{2}$ Along with the higher-class hotels and motels, they frequently serve as contact points for the negotiation and conduct of commercial sex (Jenkins 1994; UNAIDS 2000; see Hammar this volume, Pantumari and Bamne this volume). But not everyone at the Three-Mile Guesthouse that afternoon was involved in the buying and selling of sex. Many were there simply to enjoy a beer from the bar and listen to the live band. Some of the young women were related to band members and turned up to support their kin in typical Papua New Guinea fashion. Some were there for the first time, brought by a girlfriend or relative. Some could not even afford the two kina ${ }^{3}$ entry fee and peeped in through the gate to the yard, where older women sold cooked food, cigarettes and buai (betel nut). Some, men and women, were guesthouse staff; entire families, including children, were in long-term residence.

The raid was conducted in the style often used for raids on urban settlements, which involves a dramatic 'code-name', advance notification to the press, and other high-profile display tactics, all designed to bring to the attention of the public the job the police are doing in maintaining law and order (for a description of such raids, see Goddard 2001). In this case, that public display involved not just a lot of violence, looting and rape at the guesthouse itself, and mass arrests of almost everyone on the premises, but a public parade of those arrested through the streets of Boroko to the police station. The women were forced to chew and swallow condoms, blow them up, and wave them above their heads while a crowd of onlookers heckled them.

The Metropolitan Police Commander claimed that the raid was designed to prevent sex workers from contracting and spreading HIV. The women and girls arrested were charged with 'living on the earnings of prostitution', a charge which is the basis of the current criminalisation of sex work (see Fletcher and Gonapa this volume). The evidence produced in support of this charge was that condoms had been found on the premises and in their possession, which supposedly proved that the premises were a brothel and the women were prostitutes. ${ }^{4}$

What could the law do to mitigate this tragic event? What could it do to redress the wrongs committed that day, and to prevent any recurrences? Did it, could it, have any role at all?

2 Some 15-20 in Port Moresby at present.

3 Around AUD80\&. One PGK (Papua New Guinea kina) = approximately 0.42 AUD (January 2005).

4 This term is used because it is the language of the law. For some of the difficulties defining 'prostitute' or its loose synonym 'sex worker' in the Papua New Guinea context, see Hammar this volume. 
As it turned out, the charges had to be dropped, but only on a technicalitythe police were so eager to embark on their (law enforcement?) mission of social reform that somebody forgot to obtain the necessary search warrant (Anon. 2004; Yiprukaman 2004d). So the women went free. Apart from a condemnatory statement by the Internal Security Minister, who is responsible for the police (Yiprukaman 2004c), there has been no public announcement of any repercussions against those who ordered and conducted the raid. But was there, is there, anything further that could be done?

First, of course, is the possibility of action for abuse of human rights. The constitutionally-guaranteed rights to liberty and freedom and specifically freedom from inhuman treatment and from arbitrary search and entry have all possibly been infringed. In Papua New Guinea, any person can take an action in the National Court on behalf of any other person whose constitutional rights have been infringed, even without that other person's consent. So, for example, a rights advocacy group or church-based support group could easily take action on the women's behalf. Damages could be claimed, and importantly for present purposes, the whole matter of the police action, its style and its motivation, could be thoroughly examined in open court.

Action could also be taken for any number of criminal offences, such as assault and theft. But given the history of persecution of sex workers by the police in recent years (UNAIDS 2000), it is unlikely that such action would have serious repercussions for those involved. Although complaints of police mistreatment of prostitutes have on occasion been successful in the past (PNGIMR 1997, 9; cf. Jenkins this volume) overall, the chances today of a group of alleged prostitutes bringing successful complaints against the police are not good. This view is reinforced by the fact that prostitution is still criminalised in PNG. Although decriminalisation might not bring about an immediate reform in police attitudes, it might nevertheless remove the legal basis for police regarding their actions as justified. This is not to say that the treatment of the women by the police, including their being forced to suffer the indignity of the 'condom parade', was legitimate. But criminalisation can produce a simple equation in the minds of many people, including the police: these people are criminals and police protect society by apprehending criminals. 'Do what it takes to achieve this', so runs the thinking, 'we have the authority of the State on our side, as manifest in the law' (cf. Luker and Dinnen this volume, chapter one).

In fact, the law criminalising prostitution is somewhat shaky (see Fletcher and Gonapa this volume). Shortly after independence, the Law Reform Commission sought to abolish any offence of prostitution or soliciting and recommended the retention only of the related offences of operating a brothel and pimping or touting, described as 'living on the earnings of prostitution' (Law Reform Commission 1975). In 1978, however, an expatriate judge decided that this 
applied to the prostitute herself. ${ }^{5}$ However, it is hard to imagine, in the ThreeMile Guesthouse Raid, how the police intended to sustain a prosecution for living on the earnings of prostitution when the only evidence of this was to be possession of condoms. It could have made for an extremely interesting case, in which the 1978 decision could possibly have been challenged if a conviction had gone on appeal to the National Court.

Decriminalisation of prostitution was advocated in the Medium Term Plan 1998-2002 (PNG/UN 1998, 34) and has been urged by the National AIDS Council since 2000. Action in this regard is underway, with draft changes to the legislation governing sex work and homosexuality prepared for preliminary discussion in 2010 (Papik 2010). But it may be a long and hard road (see Fletcher and Gonapa this volume). Political will in this regard is almost non-existent, and this is a classic example of the difficulties of persuading the general community that repressive laws merely add fuel to the epidemic. Even if the law were to be successfully amended, the stigma would remain, and Hammar (this volume) and Fletcher and Gonapa (this volume) allude to other difficulties.

But decriminalisation of prostitution would not assist in relation to other criminalised or stigmatised activity. Homosexuality, for instance, in the form of a charge of sodomy, is still a crime in Papua New Guinea (Criminal Code Section 210), and although there are few cases actually brought to court, the threat, and the very real possibility of being framed for ulterior motives, such as dismissal from employment, is enough to make life quite uncomfortable for gay men, both national and expatriate, in Papua New Guinea. Abortion too is illegal (Criminal Code Section 225). This denies a woman control of her sexual and reproductive rights, an issue that was mentioned in the International Guidelines regarding HIV/AIDS (UNHCR/UNAIDS 1996). It is all very well advocating drug supply for pregnant women, but what of an HIV-positive woman who does not wish to bring a potential AIDS orphan into the world? In the Papua New Guinea context, she can hardly rely on a guaranteed supply of drug therapy to sustain her until her child attains majority.

\section{Efforts so far}

One almost-successful move towards the creation of an enabling legal environment for epidemic management was the passing by Parliament in 2003 of the HIV/AIDS Management and Prevention Act (HAMP Act). After considerable consultation in 2001, this law was prepared to reflect, as far as was possible, the recommendations of the International Guidelines.

5 In Anna Wemay \& Ors. v Kepas Tumdual: [1978] PNGLR 173. 
The first and principal aims of the Act are to reduce the barriers to beneficial change caused by discrimination and stigmatisation. HIV/AIDS discrimination may be directed not only against those infected, but also against their relatives and associates. So the scope of those to be protected may be likened to a series of widening circles: first, a person with HIV or AIDS; next, a person presumed to have HIV or AIDS; next, a relative or associate of a person with HIV or AIDS; then a relative or associate of a person presumed to have HIV or AIDS; and last comes a particularly important category, that of people who are or are presumed to be members of or associated with groups, activities or professions or living in environments, which are associated with or presumed to be associated with HIV infection or transmission. This last category is so important because it provides a 'back-door' way of protecting those involved in or with criminalised or stigmatised activities and groups, such as prostitutes, gay men, urban 'squatter settlement' residents, even as broad a social category as 'women'.

The second measure is the prohibition on withholding, without reasonable excuse such as unavailability, any means of protection against infection. This could include HIV/AIDS awareness materials, condoms and lubricant, sterile skin-penetrative equipment, and so on.

Next, the HAMP Act prohibits any kind of mandatory, coerced or otherwise involuntary HIV testing. This was a matter of the greatest concern to the framers of the National HIV/AIDS Medium-Term Plan 1998-2002 (PNG/UN 1998), so care was taken to ensure that testing without full voluntary informed consent could only be carried out in the most limited circumstances.

The final significant enabling measure in the Act is the protection of confidentiality regarding a person's HIV status. Obviously this restriction cannot be applied to the whole of society, but it is applied to anyone who comes by the knowledge of HIV status in the course of his or her official duties, even if these are not directly related to health or other care. Courts have the power to close their doors where appropriate. Contact-tracing and partner-notification are discretionary and may only be carried out by professional carers in limited circumstances.

So how can these grand statements of dos and don'ts be made effective? The first step is to set out what should happen if they are breached. The Act allows a wide range of remedies, depending on what particular wrong has been done. Redress can be obtained by civil or criminal court action, or where appropriate, through professional misconduct or disciplinary hearings. The range of civil remedies is very wide: as well as orders for damages, restitution and apologies, the courts may make orders to do what has not been done or to refrain from doing that which was done; to provide what has been withheld; to restore what has been taken away; to do whatever is necessary to redress any loss or damage suffered. 
But court action is not always appropriate, or even feasible. So the Act permits another avenue, that of inquiry by the Ombudsman Commission, in accordance with its jurisdiction over discriminatory practices. This is possibly the single most significant feature of the Act. Although the Commission has no power to take direct action, it can nevertheless make recommendations as appropriate, whether to public authorities or private persons. And the Ombudsman Commission of Papua New Guinea has, over the years, established a reputation for fearless and forthright investigation and action. It is a force to be reckoned with.

Unfortunately though, the Act was not in force at the time of the raid, so it will be of no assistance to the aggrieved victims of the Three-Mile Guesthouse Raid. However, the Raid does seem to have galvanised efforts to progress the legislation, and the Act was finally gazetted for commencement in September 2004. The only actions taken so far as a result of the commencement were a charge, enabled by the Act, of manslaughter for an accusation of infection by injection, (dismissed in January 2005 for lack of evidence (Faiparik 2005)) and the conviction of a man for proclaiming that his formar girlfriend was HIV positive (Kelola 2009). Further tests of its efficacy are sure to come. What usually happens with a new legislative regime is that after one or two good test cases, or in this case Ombudsman Commission inquiries, with appropriate media attention, the message starts to get out. Gradually, employers might stop sacking positive employees. Doctors and laboratories might stop giving out test results to third parties. Access to condoms might no longer be barred. And the police may no longer think they have a right, in the name of preventing HIV and AIDS, to swoop on suspected brothels, empty the tills, use violence and march women in a parade of humiliation through the streets of the nation's capital.

Another recent move towards improving the legal situation as regards sexual offences has been the Criminal Code (Sexual Offences and Crimes Against Children) Act of 2002. This Act was drawn up by the Family and Sexual Violence Action Committee headed by Lady (now Dame) Carol Kidu. It is a sad comment on the state of law reform in Papua New Guinea that Carol Kidu, although she is the government Minister for Community Development and therefore deeply involved in the social aspects of matters such as sexual violence and child prostitution, could only get this law through Parliament by proposing it as a Private Member's Bill. Why? Because it amends the Criminal Code in several significant ways; the Criminal Code is part of the Justice Minister's portfolio; and the Department of Justice and Attorney-General are not overly concerned with the promotion of social welfare amendments.

However, the Act did pass Parliament. It is the only major amendment to the sexual offences aspects of the Code since its first introduction into Papua New Guinea some hundred years ago. It makes such overdue amendments as rendering 
many of the sexual assault offences gender-neutral, whereas previously, for example, it was impossible for a male person to be raped. It makes marital rape a crime. And it inserts two new Divisions dealing with sexual offences against children and offences of child sex trafficking. A new Section 229Q makes it an offence to prosecute a child under the age of 18 years for prostitution, but unfortunately the amendment was worded so as to restrict its ambit solely to prostitution offences under the new law. When the legal team assisting those arrested in the Three-Mile Guesthouse Raid attempted to have the charges against nine under-aged girls dismissed, they were unsuccessful, as the charges had been laid under different legislation, the Summary Offences Act (Chapter 264). This is one small example of the power of the law, and the form of the law, in dictating the fundamental ways in which people's lives are shaped, and in this case, maintaining a barrier against effective social action.

\section{Conclusion}

This chapter has tried to demonstrate that the law, despite significant shortcomings of implementation and access, has a role to play in shaping society and social action. The law can enable - and disable - many things. This is essentially the role of any law. It can provide the legal characteristics of an enabling environment by removing legal barriers to effective action and by establishing legal barriers to adverse outcomes. Stigma and discrimination may remain, but at least they will no longer be reinforced by repressive legislation. The task for law reformers now is to identify further law which needs changing or improving, and to support as far as possible the creation of social and political environments in which law can take effect.

\section{References}

Anon. 2004. Police Withdraw Case against 40 women. The National, 8 April 2004.

Faiparik, Clifford. 2005. Manslaughter Charge against Soldier Dismissed. The National, 23 January 2005.

Goddard, M. 2001. From Rolling Thunder to Reggae: Imagining Squatter Settlements in Papua New Guinea. Contemporary Pacific 13: 1-32.

Hershey, Christopher. 2004. Statement of Facts on Police Raid at 3-Mile Guesthouse 12 March 2004, and Related Incidents. Statement made on behalf of Poro Sapot Project, Save the Children in Papua New Guinea, 20 March 2004. 
Jenkins, C. 1994. Situational Assessment of Commercial Sex Workers in Urban Papua New Guinea. Prevention Research Unit/GPA. New York: World Health Organisation.

Jenkins, C., and S. Sarkar. 2004. Creating Environments that Care: Interventions for HIV Prevention and Support for Vulnerable Populations (draft). Policy Project (USAID) and UNAIDS.

Kelola, Todagia. 2009. Hefty Penalty. Post-Courier, 26 May 2009

Law Reform Commission of Papua New Guinea. 1975. Report on Summary Offences. Report No. 1. Waigani: Law Reform Commission of Papua New Guinea.

Merry, S. E. and D. Brenneis. 2004. Law and Empire in the Pacific: Fiji and Hawai'i. Santa Fe, New Mexico: School of America Research Press.

Norrie, Alan W. 1993. Crime, Reason and History: A Critical Introduction to Criminal Law. London: Weidenfeld and Nicolson.

Papik, John. 2010. PNG Civil Groups Prepare Gay, Sex Work Law Challenge. Pacific Beat, Radio National, Australian Broadcasting Commission. 29 January.

Pilombo, Peku. 2004. Police Arrest 80 in Brothel Raid. The National, 15 March 2004.

PNG and NAC. 2006. Papua New Guinea National Strategic Plan on HIV/AIDS 2006-2010. Port Moresby: Government of Papua New Guinea and PNG National AIDS Council Secretariat.

PNG/UN. 1998. National HIV/AIDS Medium Term Plan 1998-2002. Port Moresby: Government of PNG with assistance from the United Nations System.

PNGIMR. 1997. Final Report to UNAIDS: Police and Sex Workers in Papua New Guinea. 12 October 1977, Goroka: Papua New Guinea Institute of Medical Research.

http://www.walnet.org/csis/papers/jenkins_papua.html (accessed 27 April 2010).

SPC (Secretariat of the Pacific Community). 1997. Regional Strategy for the Prevention and Control of STD/AIDS in Pacific Island Countries and Territories. Noumea: South Pacific Commission. 
Tawil, O.A. Verster and K.R. O'Reilly. 1995. Enabling Approaches for HIV/AIDS prevention: can we modify the environment and minimize the risk? AIDS 9: 1299-1306.

UNAIDS. 2000. Female Sex Worker HIV Prevention Projects: Lessons Learnt from Papua New Guinea, India and Bangladesh. In UNAIDS Best Practice Collection. Geneva: UNAIDS.

UNAIDS/IPU. 1999. Handbook for Legislators on HIV/AIDS, Law and Human Rights: Action to Combat HIV/AIDS in View of its Devastating Human, Economic and Social Impact. Geneva: Joint United Nations Programme on HIV/AIDS and Inter-Parliamentary Union.

UNHCHR/UNAIDS. 1996. HIV/AIDS and Human Rights: International Guidelines. New York and Geneva: United Nations Commissioner for Human Rights and Joint United Nations Programme on HIV/AIDS.

Yiprukaman, Michelle. 2004a. Sex Workers on Parade. Post-Courier, 15 March 2004.

Yiprukaman, Michelle. 2004b. Males 'Freed' ... but 31 Suspected Female Prostitutes Charged! Post-Courier, 16 March 2004.

Yiprukaman, Michelle. 2004c. Police Actions Damned. Post-Courier, 19 March 2004.

Yiprukaman, Michelle, 2004d. Police Withdraw Prostitute Case. Post-Courier, 8 April 2004. 